\title{
Peranan Orientasi Pasar dalam Hubungan Kinerja Perusahaan pada Industri Manufaktur di Solo Raya
}

\author{
Aris Tri Haryanto*, Septiana Novita Dewi, Anggoro Panji Nugroho \\ Sekolah Tinggi Ilmu Ekonomi Adi Unggul Bhirawa Surakarta, Surakarta, Indonesia \\ *arisharyanto26@yahoo.co.id
}

\begin{abstract}
This study aims to provide additional benefits to the literature on the role of market orientation on the performance relationship of manufacturing industrial companies in Solo Raya. This type of research is a causality study with a sample size of 100 respondents, which is obtained from 5 times the number of parameters (20). The research uses path analysis which has a direct or indirect effect. The results of this study indicate: 1) responsive market orientation has a significant positive effect on marketing performance, 2) proactive market orientation has a significant positive effect on marketing performance, 3) responsive market orientation has a significant positive effect on financial performance, 4) Complaint handling has no significant negative effect on financial performance, 5) Marketing performance has a significant positive effect on financial performance. The result of the direct effect of responsive market orientation on financial performance is smaller than the indirect effect. The direct effect of proactive market orientation on financial performance is smaller than the indirect effect. It shows that all are effective through direct channels without going through the mediating variable.
\end{abstract}

Keywords: Financial Performance, Marketing Performance, Proactive Market Orientation, Responsive Market Orientation

\section{PENDAHULUAN}

Di peradapan baru dimana semakin banyaknya pesaing bisnis yang semakin bermunculan, maka perlu perusahaan memperbaiki kinerja bisnisnya, agar mampu bersaing di era milineal saat ini. Perkembangan teknologi di era globalisasi yang pesat membuat konsumen mudah mendapatkan segala informasi, sehingga pelaku bisnis juga harus bisa menanfaatkan teknologi untuk dalam bisnis yang dijalankannya.
Penelitian ini membahas klasifikasi orientasi pasar diantaranya adalah orientasi pasar yang bersifat responsif dan orientasi pasar yang bersifat proaktif. Narver et al., (2004) mengungkapkan bahwa studi yang membuat klasifikasi orientasi pasar ini masih sangat minim, sehingga perlu ada penelitian lanjutan untuk mempelajari konstruksi, pendahulu, maupun konsekuensi dari klasifikasi orientasi pasar yang terbagi menjadi orientasi pasar bersifat responsif dan orientasi pasar bersifat proaktif. 
Tabel 1. Research Gap Hubungan antara Orientasi Pasar dan Kinerja

\begin{tabular}{|c|c|c|c|}
\hline Research Gap & Isu & Pembahasan & Peneliti \\
\hline $\begin{array}{l}\text { Terdapat } \\
\text { keterbatasan } \\
\text { jumlah riset } \\
\text { terdahulu yang } \\
\text { mengklasifikasi } \\
\text { kan dua jenis } \\
\text { orientasi pasar } \\
\text { (responsif dan } \\
\text { proaktif) dalam } \\
\text { hubungan } \\
\text { orientasi pasar } \\
\text { terhadap kinerja } \\
\text { inovasi }\end{array}$ & $\begin{array}{l}\text { Pengklasif } \\
\text { ikasian } \\
\text { jenis } \\
\text { orientasi } \\
\text { pasar }\end{array}$ & $\begin{array}{l}\text { Pengklasifikasian } \\
\text { tiga jenis orientasi } \\
\text { pasar (customer } \\
\text { orientation, } \\
\text { kompetitor } \\
\text { orientation, dan } \\
\text { interfuncional } \\
\text { coordination) }\end{array}$ & $\begin{array}{l}\text { Jin et al. } 1996 \\
\text { Augusto dan } \\
\text { Coelho, 2007; } \\
\text { Cheng dan } \\
\text { Krumwiede, } \\
\text { 2012; Zhou et } \\
\text { al., } 2008\end{array}$ \\
\hline
\end{tabular}

Berdasarkan hasil penelitian pada Tabel. 1 di atas maka perlu penelitian lebih lanjut. Penelitian ini melakukan analisis untuk mengetahui pengaruh orientasi pasar yang terbagi menjadi dua yaitu orientasi pasar responsif dan orientasi pasar proaktif dalam hubungannya dengan kinerja perusahaan.

Adapun konteks studi yang dipilih adalah industri manufaktur di Solo Raya. Hal ini terkait dengan kondisi dimana terdapat gejala positif dari kebangkitan industri manufaktur di Indonesia, khususnya untuk wilayah Eks. Karesidenan Surakarta. Oleh karena itu, penelitian ini dilakukan untuk mengetahui sejauh manakah potensi dari industri manufaktur di Solo Raya dapat dikembangkan, khususnya dihubungkan dengan penerapan strategi bisnis yang berbasis inovasi agar dapat meningkatkan kinerja perusahaan secara maksimal. Penelitian ini bertujuan melakukan uji empiris terkait peranan orientasi pasar dalam hubungan kinerja perusahaan pada industri manufaktur di Solo Raya.

Penelitian ini diharapkan dapat menjelaskan research gap dan dapat memberikan jawaban terkait strategi yang tepat untuk meningkatkan kinerja dalam sebuah organisasi. Penelitian ini diharapkan dapat dijadikan acuan dalam mengembangkan kinerja pemasaran dan kinerja keuangan melalui peningkatan orientasi pasar dan melakukan inovasi khususnya pada industri manufaktur di Solo Raya.

\section{METODE}

Jenis penelitian ini adalah penelitian kausalitas yaitu penelitian yang mengetahui hubungan sebab (cause) akibat (effect) antar beberapa variabel (Ferdinant, 2006) yaitu variabel orientasi pasar responsif, orientasi pasar proaktif, kinerja pemasaran dan kinerja keuangan.

Populasi dalam penelitian ini adalah industri manufaktur di wilayah Solo Raya. Wilayah Solo Raya yang menjadi sentra industri manufaktur adalah terdiri dari tujuh kabupaten yaitu Surakarta, Sragen, Karanganyar, Sukoharjo, Wonogiri, Klaten dan Boyolali. Teknik teknik pengambilan sampel berdasarkan snow-ball sampling yaitu pengambilan sampel dari anggota populasi yang dilakukan secara berantai berdasarkan imformasi awal dari beberapa industri manufaktur yang menjadi penetapan awal. Jumlah responden ditentukan berdasar 5 kali jumlah indikator $(5 \times 20)$ yaitu 100 responden.

Penelitian ini menggunakan tiga jenis variabel, yaitu: 1) variabel independen yang terdiri dari orientasi pasar responsif dan orientasi pasar proaktif, 2) variabel mediasi kinerja pemasaran, dan 3) variabel dependen kinerja keuangan. Penelitian ini bertujuan untuk menganalisi sejauh mana pengaruh secara langsung orientasi pasar responsif dan orientasi pasar proaktif terhadap kinerja dan pengaruh tidak langsung orientasi pasar responsif dan orientasi pasar proaktif terhadap kinerja keuangan melalui kinerja pemasaran.

\section{HASIL DAN PEMBAHASAN}

Hasil analisa data analisis jalur pertama ditunjukkan pada Tabel 2 berikut ini.

Tabel 2. Hasil Analisis Jalur (Path Analysis) Pertama

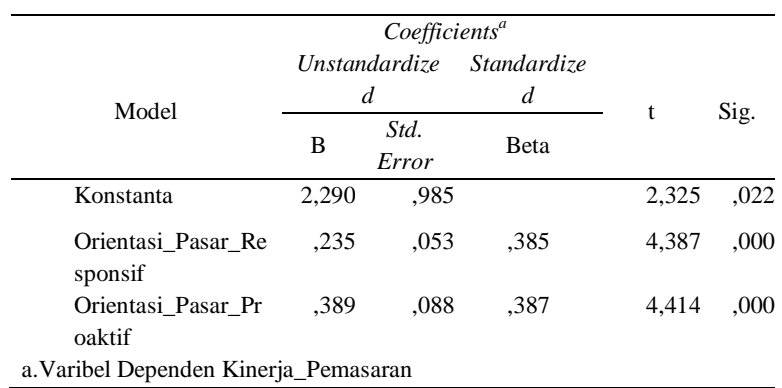

Sumber : Data yang diolah, 2020 
Dari Tabel 2. dapat dirumuskan persamaan regresi pertama:

$$
Y_{1}=0,385 X_{1}+0,387 X_{2}
$$

Hasil tersebut menunjukkan: 1) Nilai koefisien regresi orientasi pasar responsif $\left(\beta_{1}\right)$ sebesar 0,385. Hal ini menunjukkan bahwa orientasi pasar responsif berpengaruh positif terhadap kinerja pemasaran perusahaan pada industri manufaktur di Solo Raya. Ini berarti bahwa apabila orientasi pasar responsif ditingkatkan, maka kinerja pemasaran akan meningkat; 2) Nilai koefisien regresi orientasi pasar proaktif $\left(\beta_{2}\right)$ sebesar 0,387 . Hal ini menunjukkan bahwa orientasi pasar proaktif berpengaruh positif terhadap kinerja pemasaran perusahaan pada industri manufaktur di Solo Raya. Ini berarti apabila orientasi pasar proaktif pengusaha ditingkatkan, maka kinerja pemasaran perusahaan pada industri manufaktur di Solo Raya akan meningkat.

Hasil analisa data analisis jalur pertama ditunjukkan pada Tabel 3 berikut ini.

Tabel 3. Hasil Analisis Jalur (Path Analysis) Kedua

\begin{tabular}{|c|c|c|c|c|c|}
\hline & & efficien & & & \\
\hline Model & $\begin{array}{r}\text { Unstan } \\
\qquad \mathrm{c}\end{array}$ & $\begin{array}{l}\text { lardize } \\
\text { Std. }\end{array}$ & $\begin{array}{l}\text { Standardiz } \\
\text { ed }\end{array}$ & $\mathrm{t}$ & Sig. \\
\hline & B & Error & Beta & & \\
\hline Konstanta & ,553 & ,689 & & ,803 &, 424 \\
\hline $\begin{array}{l}\text { Orientasi_Pasar__ } \\
\text { Responsif }\end{array}$ & ,118 & ,040 & , 146 & 2,962 & ,004 \\
\hline $\begin{array}{l}\text { Orientasi_Pasar_ } \\
\text { Proaktif }\end{array}$ &,- 051 & ,066 &,- 038 &,- 773 & ,442 \\
\hline Kinerja_Pemasaraı & 1,139 & ,069 & ,856 & 16,477 & ,000 \\
\hline
\end{tabular}

Sumber : Data yang diolah, 2020

Dari Tabel 3 dapat dirumuskan persamaan regresi kedua:

$$
Y_{2}=0,146 X_{1}-0,038 X_{2}+0,856 X_{3}
$$

Hasil tersebut menunjukkan: 1) Nilai koeefisien regresi orientasi pasar responsif $\left(\beta_{1)}\right.$ sebesar 0,146 Hal ini menunjukkan orientasi pasar responsif berpengaruh positif terhadap kinerja keuangan perusahaan pada industri manufaktur di Solo Raya; 2) Nilai koefisien regresi orientasi pasar proaktif $\left(\beta_{2}\right)$ sebesar -0,038. Hal ini menunjukkan orientasi pasar proaktif mempunyai pengaruh negatif terhadap kinerja keuangan perusahaan pada industri manufaktur di Solo Raya; 3) Nilai koefisien regresi kinerja pemasaran $\left(\beta_{3}\right)$ sebesar 0,856. Hal ini menunjukkan bahwa kinerja pemasaran berpengaruh positif terhadap kinerja keuangan perusahaan pada industri manufaktur di Solo Raya.

Hasil pada Tabel 2 dan Tabel 3 juga menunjukkan: 1) Orientasi pasar responsif dan proaktif berpengaruh positif signifikan terhadap kinerja pemasaran. Hal ini terlihat dari nilai signifikansi $<0,05$; 2) Orientasi pasar responsif dan kinerja pemasaran berpengaruh positif signifikan terhadap kinerja keuangan. Hal ini dapat dilihat dari nilai signifikansi dari masing-masing variabel $<0,05$; dan 3) Orientasi pasar proaktif berpengaruh negatif tidak signifikan terhadap kinerja keuangan.

\begin{tabular}{|c|c|c|c|c|c|}
\hline & $\begin{array}{r}C \\
\text { Or } \\
\mathrm{Pas}\end{array}$ & $\begin{array}{l}\text { relatic } \\
\text { ntasi_ } \\
\text { r_resp }\end{array}$ & $\begin{array}{l}\text { Ons } \\
\text { Orientas } \\
\text { i_Pasar_. }\end{array}$ & Kinerja_Pe & Kinerja_K \\
\hline & & sif & Proaktif & masaran & euangan \\
\hline Orientasi_Pa & Pearson & 1 &, $516^{* * *}$ &, $585^{* *}$ & $.627^{* * *}$ \\
\hline sar_responsif & Correlation & & & & \\
\hline & Sig. (2-tailed) & &, 000 &, 000 &, 000 \\
\hline & $\mathrm{N}$ & 100 & 100 & 100 & 100 \\
\hline Orientasi_Pa & Pearson & .516 & 1 &, $586^{* *}$ &, $539^{* *}$ \\
\hline sar_Proaktif & Correlation & ** & & & \\
\hline & Sig. (2-tailed) & .000 & & ,000 & ,000 \\
\hline & $\mathrm{N}$ & 100 & 100 & 100 & 100 \\
\hline Kinerja_Pem & Pearson & .585 & $.586^{* *}$ & 1 &, $919^{* * *}$ \\
\hline asaran & Correlation & ** & & & \\
\hline & Sig. (2-tailed) & .000 & ,000 & &, 000 \\
\hline & $\mathrm{N}$ & 100 & 100 & 100 & 100 \\
\hline Kinerja_Keu & Pearson & .627 &, $539^{* * *}$ &, $919^{* *}$ & 1 \\
\hline angan & Correlation & ** & & & \\
\hline & Sig. (2-tailed) & .000 &, 000 & ,000 & \\
\hline & $\mathrm{N}$ & 100 & 100 & 100 & 100 \\
\hline
\end{tabular}

Tabel 4. Koefisien Korelasi

Sumber : Data yang diolah, 2020

Berdasar Tabel 4, dapat dijelaskan hubungan antar variabel yaitu: 1) Hubungan orientasi pasar responsif terhadap kinerja pemasaran perusahaan pada industri manufaktur di Solo Raya adalah cukup kuat sebesar 0,585 ; 2) Hubungan orientasi pasar proaktif terhadap kinerja pemasaran perusahaan pada industri manufaktur di Solo Raya cukup kuat sebesar 0,586; 3) Hubungan orientasi pasar responsif dengan kinerja 
keuangan perusahaan pada industri manufaktur di Solo Raya adalah kuat nilai korelasi sebesar 0,627 ; 3) Hubungan orientasi pasar proaktif dengan kinerja keuangan perusahaan pada industri manufaktur di Solo Raya cukup kuat dengan nilai korelasi 0,539 ; dan 4) Hubungan kinerja pemasaran dengan kinerja keuangan perusahaan pada industri manufaktur di Solo Raya adalah sangat kuat dengan nilai korelasi sebesar 0,919.

Tabel 5 menjelaskan hasil analisis jalur yang menjelaskan pengaruh langsung, pengaruh tidak langsung dan pengaruh total.

Tabel 5. Hasil Analisis Jalur

\begin{tabular}{lcclcc}
\hline \multirow{2}{*}{ Variabel } & \multicolumn{2}{c}{ Koefisien Jalur } & \multirow{2}{*}{ Total Pengaruh } & $\begin{array}{c}\text { Test } \\
\text { Statistic }\end{array}$ & $\begin{array}{c}\text { P- } \\
\text { value }\end{array}$ \\
\cline { 2 - 3 } & DE & IE & & 4,387 & 0,000 \\
$\mathrm{X}_{1} \mathrm{ke} \mathrm{Y}_{1}$ & 0,385 & & & 4,414 & 0,000 \\
$\mathrm{X}_{2} \mathrm{ke} \mathrm{Y}_{1}$ & 0,387 & & & 2,962 & 0,004 \\
$\mathrm{X}_{1} \mathrm{ke} \mathrm{Y}_{2}$ & 0,146 & & $-0,773$ & 0,442 \\
$\mathrm{X}_{2} \mathrm{ke} \mathrm{Y}_{2}$ & $-0,038$ & & & 16,477 & 0,000 \\
$\mathrm{Y}_{1} \mathrm{ke} \mathrm{Y}_{2}$ & 0,856 & & & \\
$\mathrm{X}_{1}-\mathrm{Y}_{1}-$ & & $=0,385 \times 0,856$ & $=0,146+0,329$ & & \\
$\mathrm{Y}_{2}$ & & $=0,329$ & $=0,475$ & & \\
$\mathrm{X}_{2}-\mathrm{Y}_{2}-$ & & $=0,387 \times 0,856$ & $=(-0,038)+0,331$ & & \\
$\mathrm{Y}_{2}$ & & $=0,331$ & $=0,293$ & & \\
\hline
\end{tabular}

Sumber : Data yang diolah, 2020

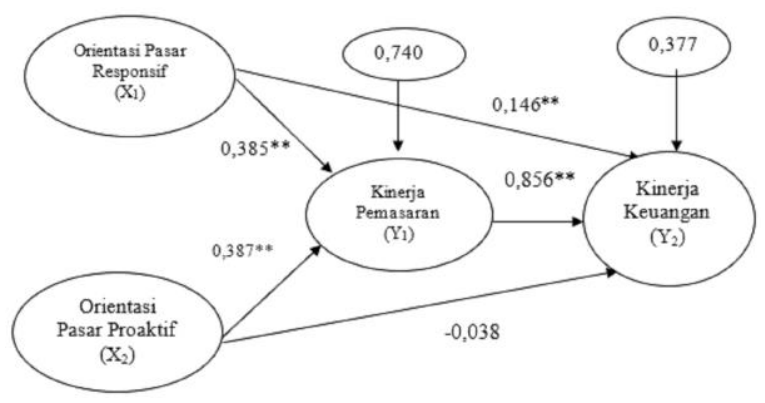

Gambar 1. Hasil Kerangka Pemikiran Akhir

\section{Hubungan Orientasi Pasar Responsif terhadap Kinerja Pemasaran

Orientasi Pasar \\ Responsif}

berpengaruh positif dan signifikan terhadap kinerja pemasaran. Hal ini berarti apabila orientasi pasar responsif ditingkatkan, maka kinerja pemasaran juga akan semakin meningkat. Hal ini berarti kinerja pemasaran akan semakin meningkat apabila perusahaan selalu cepat dalam merespon pasar, mengetahui dengan cepat perkembangan pasar dan apa yang diinginkan konsumen pada saat ini. Dengan adanya sikap yang responsif terhadap perubahan pasar, maka kinerja pemasaran perusahaan akan terlihat dengan baik bagaimana proses perusahan dalam menjalankan startegi pemasarannya. Hal ini sesuai teori yang disampaikan Kohli dan Jaworski (1990) bahwa kebutuhan konsumen akan selalu berkembang, sehingga diperlukan sikap yang responsif terhadap keinginan konsumen, yaitu sikap yang selalu berorientasi pada pasar.

\section{Hubungan Orientasi Pasar Proaktif terhadap Kinerja Pemasaran \\ Orientasi pasar proaktif berpengaruh} positif dan signifikan terhadap kinerja pemasaran, ini berarti apabila orientasi pasar proaktif ditingkatkan, maka kinerja pemasaran juga akan semakin meningkat. Hasil ini sesuai dengan hasil penelitian yang disampaikan oleh Zhang dan Duan, (2010) bahwa kinerja pemasaran dapat dipengaruhi oleh orientasi pasar proaktif. Hasil ini dapat mengimplikasikan bahwa perusahaan harus selalu proaktif dalam mencari informasi tentang kebutuhan konsumen. Dengan adanya usaha yang lebih proaktif dalam menggali kebutuhan dan keinginan konsumen perusahaan akan dengan mudah memberikan kebutuhan konsumen, sehingga produk yang ditawarkan akan sesuai dengan keinginan konsumen.

\section{Hubungan Orientasi Pasar Responsif terhadap Kinerja Keuangan}

Hasil penelitian menunjukkan orientasi pasar responsif berpengaruh positif signifikan terhadap kinerja keuangan. Perusahaan dapat beroperasi dengan baik apabila memiliki kinerja keuangan dengan baik. Hal ini dapat diketahui bahwa kinerja keuangan merupakan kondisi keuangan perusahaan yang yang memiliki modal usaha yang cukup, tingkat likuiditas dan profitabiltas yang baik dalam menjalankan usahanya (Jumingan, 2006). Sikap responsif perusahaan terhadap analisis pasar, dapat dipengaruhi dari segi keuangan perusahaan. Apabila perusahaan mampu memenuhi biaya pemasaran dengan baik, maka proses pemasaran dalam mencari informasi kebutuhan dan keinginan konsumen akan tercapai dengan mudah. 


\section{Hubungan Orientasi Pasar Proaktif terhadap Kinerja Keuangan}

Hasil penelitian menunjukkan hasil orientasi pasar proaktif berpengaruh negatif tidak signifikan terhadap kinerja keuangan. Hal ini dapat dijelaskan apabila orientasi pasar proaktif ditingkatkan, maka kinerja keuangan perusahaan akan menurun. Voola dan O'Cass, (2010) mengemukakan bahwa kinerja perusahaan yang proaktif diperlukan dukungan perusahaan baik dari segi finansial maupun strategi pemasaran. Hal ini tidak dapat dipungkuri bahwa dalam proses pemasaran yang aktif sangat diperlukan biaya dalam proses pemasarannya, sehingga dalam penelitian ini diterapkan pada industri manufaktur di Solo Raya yang rata-rata mengeluh dalam pembiayaan dalam mengembangkan usahanya.

\section{Hubungan Kinerja Pemasaran terhadap Kinerja Keuangan}

Hasil penelitian kinerja pemasaran berpengaruh positif signifikan terhadap kinerja keuangan. Semakin tinggi kinerja pemasarannya, maka akan semakin tinggi kinerja keuangannya. Perusahaan dalam berusaha memberikan strategi-strategi yang tepat dalam mengembangkan usahanya, akan memerlukan media pemasaran yang cukup banyak dan beragam. Hal ini dapat disampaikan bahwa upaya perusahaan dalam meningkatkan pemasarannya bisa memanfaatkan adanya media online yang dalam pemasarannya tidak memerlukan biaya yang terlalu tinggi, misalnya Industri manufaktur di Solo Raya dapat memanfaatkan media sosial dalam meingkatkan program-program pemasarannya dengan memberikan inovasi-inovasi yang menarik terhadap produk yang ditawarkan.

\section{Hubungan Orientasi Pasar Responsif terhadap Kinerja Keuangan melalui Kinerja Pemasaran}

Penggunaan variabel mediasi kinerja pemasaran antara kinerja keuangan pengusaha pada industri manufaktur di Solo Raya, efektif meningkatkan orientasi pasar responsif. Dengan adanya orientasi pasar responsif yang lebih baik diharapkan kinerja keuangan perusahaan akan meningkat pada industri manufaktur di Solo Raya.

Peningkatan kinerja keuangan pengusaha industri manufaktur di Solo Raya sebaiknya menggunakan variabel orientasi pasar responsif melalui kinerja pemasaran. Langkah-langkahnya dilakukan dengan cara yaitu: 1) Meningkatkan kepuasan pelanggan pada industri manufaktur di Solo Raya dengan cara memperbaiki orientasi yang ada, 2) Meningkatkan penjualan industri manufaktur di Solo Raya dengan selalu berusaha responsif terhadap pelanggan, dan 3) Meningkatkan penguasaan pasar pada industri manufaktur di Solo Raya dengan memperbaiki pangsa pasar yang ada.

\section{Hubungan Orientasi pasar proaktif terhadap Kinerja Keuangan melalui Kinerja Pemasaran \\ Penggunaan mediasi kinerja} pemasaran efektif dalam meningkatkan kinerja keuangan melalui orientasi pasar proaktif. Kinerja keuangan pengusaha pada industri manufaktur di Solo Raya sebaiknya menggunakan variabel orientasi pasar proaktif secara tidak langsung dengan langkah-langkah: 1) Meningkatkan kepuasan pelanggan pada industri manufaktur di Solo Raya dengan memperbaiki orientasi yang ada, 2) Meningkatkan penjualan industri manufaktur di Solo Raya dengan selalu berusaha responsif terhadap pelanggan, dan 3) Meningkatkan penguasaan pasar pada industri manufaktur di Solo Raya dengan memperbaiki pangsa pasar yang ada. Peningkatan kinerja pemasaran perusahaan pada industri manufaktur di Solo Raya diharapkan akan memberikan kepercayaan kepada perusahaan sehingga dapat membantu perusahaan memperbaiki kinerja keuangannya.

\section{Kesimpulan}

Kesimpulan dalam penelitian ini adalah sebagai berikut: 1) Orientasi pasar responsif berpengaruh positif signifikan terhadap kinerja pemasaran pengusaha pada 
industri manufaktur di Solo Raya, 2) Orientasi pasar proaktif mempunyai pengaruh positif signifikan terhadap kinerja pemasaran perusahaan pada industri manufaktur di Solo Raya, 3) Orientasi pasar responsif berpengaruh signifikan dan positif terhadap kinerja keuangan perusahaan pada Industri Manufaktur di Solo Raya, 4) Orientasi pasar proaktif tidak mempunyai pengaruh signifikan terhadap kinerja keuangan perusahaan pada Industri Manufaktur di Solo Raya, 5) Kinerja pemasaran berpengaruh positif signifikan terhadap kinerja keuangan perusahaan pada Industri Manufaktur di Solo Raya, dan 6) Peran mediasi kinerja pemasaran tepat untuk meningkatkan kinerja keuangan melalui orientasi pasar proaktif.

$$
\text { Berdasar hasil penelitian, }
$$
direkomendasikan untuk meningkatan kinerja pemasaran pada industri manufaktur di Solo Raya dengan cara: 1) Meningkatkan kepuasan pelanggan pada industri manufaktur di Solo Raya dengan memperbaiki orientasi yang ada, 2) Meningkatkan penjualan industri manufaktur di Solo Raya dengan selalu berusaha responsif terhadap pelanggan, dan 3) Meningkatkan penguasaan pasar pada industri manufaktur di Solo Raya dengan memperbaiki pangsa pasar yang ada.

\section{DAFTAR PUSTAKA}

Atuahene-Gima, K., Slater, S.F. \& Olson, E.M. (2005). The contingent value of responsive and proactive market orientations for new product program performance. Journal of Product Innovation Management, 22 (6), 464 482.

Augusto, M. \& Coelho, F. (2007), "Market orientation and new-to-the-world products: exploring the moderating effects of innovativeness, competitive strength, and environmental forces", Industrial Marketing Management, 38, 94-108.

Baker, W. \& Sinkula, J. M. (2007). Does market orientation facilitate balanced innovation programs? An organizational learning perspective.
Journal of Product Innovation Management, 24 (4), 316-334.

Bodlaj, Mateja. 2010. The impact of a responsive and proactive market orientation on innovation and business performance. Economic and business review, 12(4),241-261

Cano, C.R., Carrillat, F.A. \& Jaramillo, F. (2004). A meta-analysis of the relationship between market orientation and business performance: evidence from five continents. International Journal of Research in Marketing, 21 (2), 179-200.

Damanpour, F., 1991. Organizational innovation: a meta-analysis of effects of determinants and moderators. Academy of Management Journal 34 (3), 555-590.

Deshpande, R. \& Farley, J.U. (2004). Organizational culture, market orientation, innovativeness, and firm performance: an international research odyssey. International Journal of Research in Marketing, 21 (1), 3-22.

Ellis, P. D. (2006). Market orientation and performance: a meta-analysis and cross-national comparisons. Journal of Management Studies, 43 (5), 10891107.

Griffin, A. \& Hauser, J. R. (1996). Integrating R\&D and marketing: a review and analysis of the literature. Journal of Product Innovation Management, 13 (3), 191-215.

Grinstein, A. (2008). The effect of market orientation and its components on innovation consequences: a metaanalysis. Journal of the Academy of Marketing Science, 36 (2), 166-173.

Gruca, T. S. \& Rego, L. L. (2005). Customer satisfaction, cash flow, and shareholder value. Journal of Marketing, 69 (3), 115-130.

Han, J.K., Kim, N., Srivastava, R.K., 1998. Market orientation and organisational performance: is innovation the missing link? Journal of Marketing 62 (4), 30-45. 
Homburg, C. \& Pflesser, C. (2000). A multiple-layer model of marketoriented organizational culture: measurement issues and performance outcomes. Journal of Marketing Research, 37(4), 449-462.

Hurley, R. F. \& Hult, G. T. M. (1998). Innovation, market orientation, and organizational learning: an integration and empirical examination. Journal of Marketing, 62 (3), 42-54.

Ittner, C.D., Larcker, D.F., 1997. The performance effects of process management techniques. Management Science 43, 522-534.

Johannessen, J., Olsen, B., Lumpkin, G.T., 2001. Innovation as newness: what is new, how new, and new to whom? European Journal of Innovation Management 4 (1), 20-31.

Knott, A.M., 2001. The dynamic value of hierarchy. Management Science, 47, 430-448.

Kohli, A.K., Jaworski, B. J.\& Kumar, A. (1990). MARKOR: a measure of market orientation. Journal of Marketing Research, 30 (4), 467-477.

Lawless, M.W., Anderson, P.C., (1996). Generational technological change: effects of innovation and local rivalry on performance. Academy of Management Journa,l 39, 1185-1217.

Ledwith, A. \& O'Dwyer, M. (2008). Product launch, product advantage and market orientation in SMEs. Journal of Small Business and Enterprise Development, 15 (1), 96-110.

Li, H., Atuagene-Gima, K., 2001. Product innovation strategy and the performance of new technology ventures in China. Academy of Management Journal 44 (6), 11231134.

Li, L., 2000. An analysis of sources of competitiveness and performance of Chinese manufacturers. International Journal of Operations and Production Management, 20 (3-4), 299-315.

Lin, C.Y., Chen, M.Y. (2007). Does innovation lead to performance? An empirical study of SMEs in Taiwan. Management Research News, 30 (2), 115-132.

Marcus, A.A., (1988). Responses to externally induced innovation: Their effects on organizational performance. Strategic Management Journal, 9, 387-402.

Matsuno, K., Mentzer, J. T. \& Özsomer, A. (2002). The effects of entrepreneurial proclivity and market orientation on business performance. Journal of Marketing, 66 (3), 18-32.

Mavondo, F. and Farrell, M. (2003), "Cultural orientation: its relationship with market orientation, innovation and organizational performance", Management Decision, 41(3), 241-9.

Morgan, N. A., Clark, B. H. \& Gooner, R. (2002). Marketing productivity, marketing audits, and systems for marketing performance assessment: integrating multiple perspectives. Journal of Business Research, 55 (5), 363-375.

Narver, J.C., Slater, S.F. \& MacLachlan, D.L. (2004). Responsive and proactive market orientation and new-product success. Journal of Product Innovation Management, 21 (5), 334347.

Olson, C.A., Schwab, A., (2000). The performance effects of human resource practices: the case of interclub networks in professional baseball, 1991-1940. Industrial Relations, 39, 553-577.

Pelham, A.M., (1997). Mediating influences on the relationship between market orientation and profitability in small industrial firms. Journal of Marketing Theory and Practice. 5 (3), 55-76.

Ravichandran, T., (2000). Swiftness and intensity of administrative innovation adoption: An empirical study of TQM in information systems. Decision Sciences 31 (3), 691-724.

Sandvik, I. L. \& Sandvik, K. (2003). The impact of market orientation on 
product innovativeness and business performance. International Journal of Research in Marketing, 20 (4), 355376.

Slater, S. F. \& Narver, J. C. (1994). Market orientation and the learning organization. Journal of Marketing, 59 (3), 63-74.

Srivastava, R. K., Shervani, T. A. \& Fahey, L. (1998). Market-based assets and shareholder value: a framework for analysis. Journal of Marketing, 62 (1), 2-18.

Subramanian A., Nilakanta, S., (1996). Organisational innovativeness: Exploring the relationship between organisational determinants of innovation, types of innovations, and measures of organisational performance. Omega, 24 (6), 631-647.

Vazquez, R., Santos, M. L. \& Alvarez, L. I. (2001). Market orientation, innovation and competitive strategies in industrial Firms. Journal of Strategic Marketing, 9 (1), 69-90.

Voola, R. \& O'Cass, A. (2010). Implementing competitive strategies: the role of responsive and proactive market orientations. European Journal of Marketing, 44 (1/2), 245-266.

Walker, R.M., (2004). Innovation and organizational performance: Evidence and a research agenda. Advanced Institute of Management Research Working Paper, WP, 2

Wang, E.T.G., Wei, H.-L., (2005). The importance of market orientation, learning orientation, and quality orientation capabilities in TQM: An example from Taiwanese software industry. Total Quality Management, 16 (10), 1161-1177.

Whittington, R., Pettigrew, A., Peck, S., Fenton, E., \& Conyon, M., (1999). Change and complementarities in the new competitive landscape: $A$ European panel study, 1992-1996. Organisation Science, 10, 583-600.
Wren, B. M., Souder, W. E. \& Berkowitz, D. (2000). Market orientation and new product development in global industrial firms. Industrial Marketing Management, 29 (6), 601-611.

Zhou, K.Z. (2008), "Innovation, imitation, and new product performance: the case of China", Industrial Marketing Management, 35(3), 394-402 